\title{
Technology: A safety net for high-wire acts
}

The tricks and

skills acquired

along the way

-bioinforma-

tics in genome

companies, for

example-

are saleable,

interim

products.
For many biotechnology companies, technology is the cornerstone on which they are built. Technology also distinguishes biotechnology companies from the largely product-driven pharmaceutical companies. But technology is much more than this: Under certain critical circumstances, it can cushion an unanticipated fall.

Isis Pharmaceuticals (Carlsbad, CA) managed recently to shrug off some bad clinical trial news. The company's lead compound, ISIS 2922, an antisense drug for the treatment of cytomegalovirus infections in AIDS patients, showed an adverse reaction in some patients.

Isis halted the trials and, following discussion with the U.S. Food and Drug Administration (FDA, Rockville, MD), resumed trials with a lower dose of the drug. Yet the price of Isis' stock dropped only $10 \%$ on the first day following the announcement. And, surprisingly, the price soon moved up again (from the low after the announcement) by 7 and $36 \%$ one and two weeks later.

Protein Design Labs (PDL, Mountain View, CA) was similarly resilient. Its first humanized monoclonal antibody, Zenapax, failed in phase II/III trials: The anti-Tac antibody did not reduce the incidence of graft-versus-host disease in a controlled trial of 210 patients. The company's partner, Hoffmann-La Roche (Basel) was conducting the trials and still plans to continue two phase III trial of Zenapax for the prevention of acute rejection in kidney transplant patients. On the day the bad news was announced, PDL's stock price fell $33 \%$, but it subsequently recovered, increasing 5 and $12 \%$ over the initial low in the following two weeks.

By contrast, Cor Therapeutics' (S. San Francisco, CA) stock price plummeted by $45 \%$ on the day following its bad news. Its lead compound, the platelet inhibitor Integrelin, used after angioplasty, failed in phase III trials to prevent either death or heart attacks at statistically significant levels. The company's stock price descended further in the subsequent two weeks: 8 and $14 \%$ below the low after the announcement. The drop occurred despite the fact that Cor, along with its corporate partner, Schering-Plough (Madison, NJ), is continuing Integrelin's clinical trials for other indications (unstable angina and acute heart attack).

Although market reaction to individual stocks is a combination of many factors, we believe that a major reason for the relatively mild reaction of the market to the clinical setbacks at Isis and PDL was their technology.

Platform technologies, in essence, play the same roles as platforms in a circus trapeze act. First, platforms elevate the company to a higher level from which it can display its skills in drug development. Second, they provide a jumping-off point from which biotechnology companies can form interdependent relationships with high-flying pharmaceutical firms. And third, they provide anchor points for the safety net in case of a fall.

Isis is a good example of a company with platform technology. The company's antisense technology has so far attracted corporate collaborations and large financial commitments from several industry giants: Ciba Geigy (Basel), Boehringer Ingelheim (Ingleheim), Eisai (Tokyo) and Kaketsuken/Mochida (Tokyo). Similarly, PDL, which has used its CDR grafting technology for generating chimeric and "humanized" monoclonal antibodies, has established a number of collaborations with Corange/Boehringer Mannheim (Bermuda), Hoffmann-La Roche (Basel), Yamanouchi (Tokyo), and Kanebo (Osaka).

But while Cor Therapeutics is developing several classes of platelet adhesion, thrombin synthesis, and growth factor inhibitors for various cardiovascular conditions and does have collaborations with Schering Plough, Eli Lilly (Indianapolis, IN), Ortho Pharmaceuticals (Raritan, NJ), and Kyowa Hakko Kogyo (Tokyo, Japan), the company is prod- uct driven and has no broad technology platform.

A similar scenario is seen in merger and acquisitions. Technology-driven companies are attractive to pharmaceutical companies. Witness the acquisition of Affymax, (Palo Alto, CA), a leading combinatorial library company but still one with no products in clinical development, for $\$ 540$ million by Glaxo (London); and those of gene therapy companies Genetic Therapy (Gaithersburg, MD) and Viagene (San Diego, CA) by Sandoz (Basel) and Chiron (Emeryville, CA), respectively. Genomics, too, is a platform technology that has attracted many pharmaceutical companies (see "Lilly and Millenium cut the genomics cake a new way," p.1149).

We do not wish here to downplay the value of real products. Indeed, we strongly believe that, in the long term, it is "real" products which address "real" diseases that will bring the full value to the industry and individual companies. We do, however, believe that technology development-although potentially a longer route to full value-is a lower risk approach. The tricks and skills acquired along the way-bioinformatics in genome companies, for exampleare saleable, interim, products with a definite, if difficult-to-define, value.

While the latest rally in biotech stock prices and financing has mostly focused on companies with advanced clinical stage products, perhaps it is time to refocus on some earlier-stage technologydriven companies-companies that cannot simply be valued by discounted earnings model analysis. This challenge should not be an obstacle to recognizing value.

Fariba Fischel Ghodsian is vicepresident, research and biotechnology/pharmaceutical analyst, Wedbush Morgan Securities, 1000 Wilshire Boulevard, Los Angeles, CA 90030, U.S.A. Alexander Y. Draper, a research assistant at Wedbush Morgan Securities, contributed to this commentary. 